\title{
Perceived effects of farm tractors in four African countries, highlighted by participatory impact diagrams
}

\author{
Thomas Daum ${ }^{1} \cdot$ Ygué Patrice Adegbola ${ }^{2}$ - Geoffrey Kamau ${ }^{3} \cdot$ Alpha Oumar Kergna $^{4} \cdot$ Christogonus Daudu $^{5}$. \\ Roch Cedrique Zossou ${ }^{2}$. Géraud Fabrice Crinot $^{2}$ • Paul Houssou ${ }^{2}$ - Lawrence Mose ${ }^{3} \cdot$ Yarama Ndirpaya $^{5}$. \\ A. A. Wahab ${ }^{6}$. Oliver Kirui ${ }^{7}$ - Fatunbi Abiodun Oluwole ${ }^{8}$
}

Accepted: 23 October 2020 / Published online: 23 November 2020

(C) The Author(s) 2020

\begin{abstract}
Agricultural mechanization is on the rise in Africa. A widespread replacement of manual labor and animal traction will change the face of African agriculture. Despite this potentially transformative role, only a few studies have looked at the effects of mechanization empirically, mostly focusing on yields and labor alone. This is the first paper that explores perceived agronomic, environmental, and socioeconomic effects together, thereby revealing linkages and trade-offs, some of which have been hitherto unknown. Data were collected using a novel data collection method called "participatory impact diagrams" in four countries: Benin, Kenya, Nigeria, and Mali. In 129 gendered focus group discussions, 1330 respondents from 87 villages shared their perceptions on the positive and negative effects of agricultural mechanization, and developed causal impact chains. The results suggest that mechanization is likely to have more far-reaching agronomic, environmental, and socioeconomic consequences than commonly assumed. Most perceived effects were positive, suggesting that mechanization can help to reduce poverty and enhance food security but other effects were negative such as deforestation, soil erosion, land-use conflicts, and gender inequalities. Accompanying research and policy efforts, which reflect variations in local agro-ecological and socioeconomic conditions, are needed to ensure that mechanization contributes to an African agricultural transformation that is sustainable from a social, economic, and environmental perspective.
\end{abstract}

Keywords Agricultural mechanization $\cdot$ Rural transformation $\cdot$ Tractors $\cdot$ Yields $\cdot$ Employment $\cdot$ Soil fertility $\cdot$ Deforestation . Gender · Africa

Thomas Daum

thomas.daum@uni-hohenheim.de

1 Hans-Ruthenberg-Institute of Agricultural Science in the Tropics, University of Hohenheim, Wollgraweg 43, 70599 Stuttgart, Germany

2 Institut National des Recherches Agricoles du Benin (INRAB), Cotonou, Benin

3 Kenyan Agricultural and Livestock Research Organization (KALRO), Nairobi, Kenya
4 Institut d'Economie Rurale (IER), Bamako, Mali

Agricultural Research Council of Nigeria (ARCN), Abuja, Nigeria

6 National Agricultural Extension Research \& Liaison Services, Zaria, Nigeria

Center of Development Research (ZEF), Bonn, Germany

8 Forum for Agricultural Research in Africa (FARA), Accra, Ghana 


\section{Introduction}

Many African governments have resumed supporting agricultural mechanization during the last years, particularly focusing on tractors for crop production. Governments promote mechanization through the public distribution of subsidized machinery, the creation of machinery assembly plants, and the public or public-private machinery hire schemes (Sims et al. 2016). Besides public action, there is evidence of emerging private markets for machinery and services (Daum and Birner 2020; Diao et al. 2014; Takeshima et al. 2015). Thus, while mechanization levels are still low across much of Africa (Daum and Birner 2020), this is likely to change. The recent experience of Asian countries has shown that mechanization can unfold rapidly once a real demand and enabling environment exist (Biggs and Justice 2015; Diao et al. 2014; Wang et al. 2016).

A widespread replacement of manual labor and animal traction with mechanical power would change the face of African farming and rural areas as the history of today's mechanized countries has shown (see, for example, Jansen 1969, for Europe). Many believe that mechanization has largely positive effects, for example, releasing farmers from heavy physical work and enabling higher yields (Sims et al. 2016; Malabo Montpellier Panel 2018); however, there are also fears of unemployment and land expansion at the cost of forests and savannah, among others (Daum and Birner 2020). Empirical research in Africa has mostly focused on the effects of mechanized crop production, mostly during land preparation, on yields and labor (Adu-Baffour et al. 2019; Cossar 2019; Houssou and Chapoto 2015; Kirui 2019; Mano et al. 2020), but has neglected other aspects or covered them merely "en passant." Notable exceptions are Kansanga et al. (2018) studying effects on crop diversity and farm trees and Kansanga et al. (2019) and Fischer et al. (2018) exploring gender roles, among others.

The narrow focus of the literature is alarming as organizations such as the FAO (2013) clearly emphasize the need for countries' mechanization strategies to consider all three pillars of sustainability: social, economic, and environmental. To which extent this occurs in rural villages has not been explored. Moreover, the narrow view on mechanization effects in the literature, focusing on yield and labor, makes designing good policies and programs promoting or accompanying agricultural mechanization challenging. In addition to yields and labor, mechanization may have additional effects, some of which have been rarely explored or may even be entirely unknown to researchers and policymakers. For example, mechanization may change crop diversity and food prices, and, subsequently, food and nutrition security (Kansanga et al. 2018). Moreover, the use of tractors may affect the environment. At the farm level, mechanization may affect soils and the presence of trees, for example (Benin 2015, Kansanga et al. 2019). Beyond the farm level, mechanization, which enhances the farm power available to farmers, may re-shape land-use patterns, including the presence of forests and savannah, and subsequently can also affect biodiversity and climate (Daum and Birner 2020). While some of the changes related to mechanization may be positive, others can be negative. In the latter case, complementary policy measures accompanying mechanization efforts would be needed to ensure that it unfolds in an economically, environmentally, and socially sustainable way.

The objective of this paper is to explore the perceived agronomic, environmental, and socioeconomic effects of agricultural mechanization in Africa to guide future research and policy as well as private sector efforts. The paper focuses on the use of tractors for land preparation as this was the most commonly mechanized activity across the case study countries and as this labor-intensive activity is typically mechanized first (Binswanger 1986). Data were collected with the help of qualitative methods in different regions of four African countries, namely Benin, Kenya, Nigeria, and Mali. For this, an innovative participatory data collection tool called "participatory impact diagrams" (PID) was used. PID allow the assessment of positive and negative effects related to the adoption of new technologies as perceived by community members themselves. In particular, the method allows community members to identify both direct and indirect effects through the socalled change trees (Kariuki and Njuki 2013), enabling them to develop casual impact pathways.

The advantage of such a qualitative approach is its flexible and open-ended nature, which allows respondents to share their perspectives without being guardrailed by pre-coded survey questions. This helps to gain new insights or discover new aspects that are not on the research agenda but are potentially highly relevant. Next to methodological considerations, the use of qualitative approaches also has practical benefits. While some of the aspects studied here may be quantifiable, the cost and efforts to study all the effects covered here using such methods in four countries would have been prohibitively high. Thus, this paper presents a systematic exploration of potential effects that can generate "working hypotheses" (Garbarino and Holland 2009) and provide guidance for future quantitative agronomic, environmental, and socioeconomic research. 


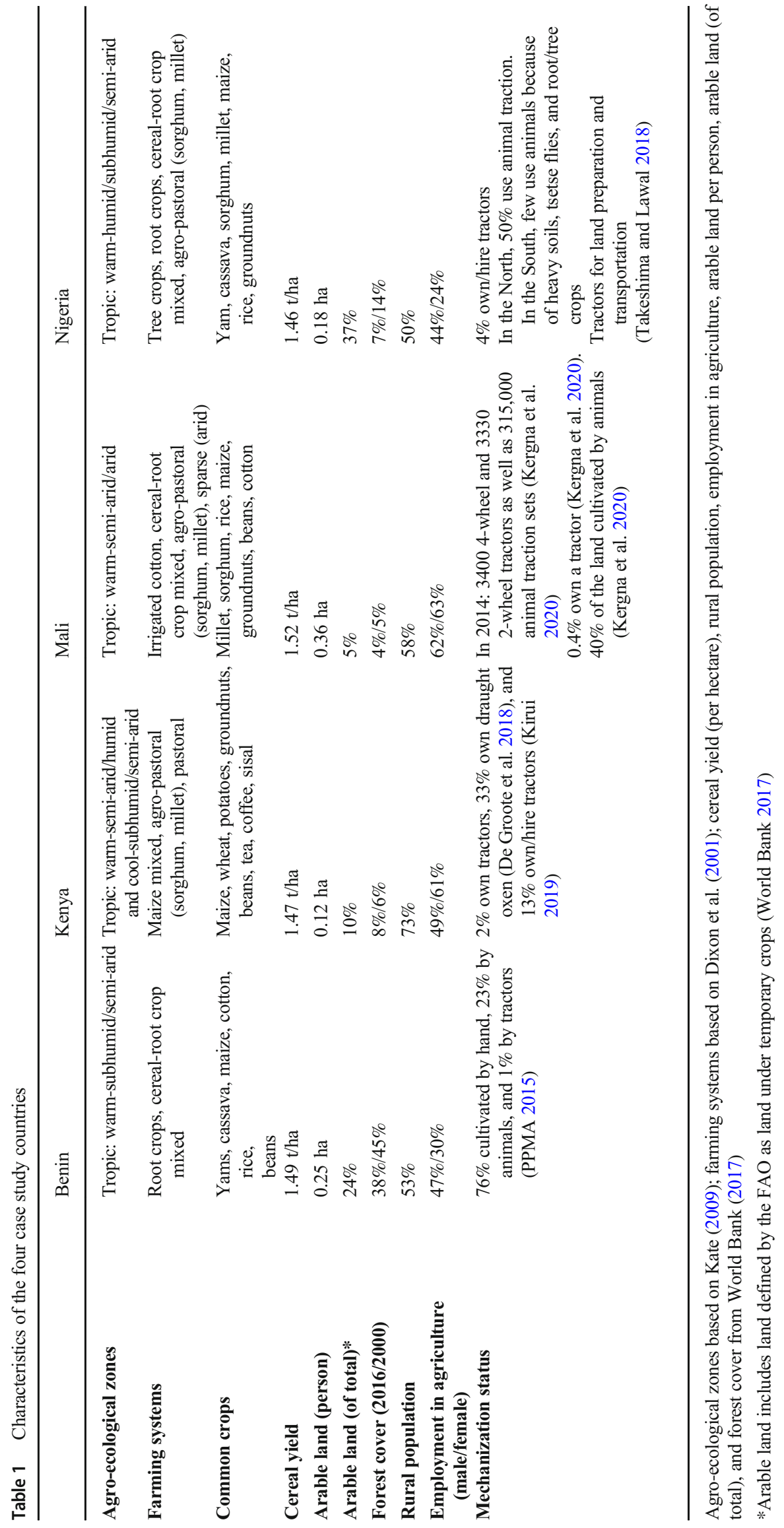

INRAP $\underline{\text { Springer }}$ 
Table 2 Sampling framework for focus group discussions (FGDs)

\begin{tabular}{|c|c|c|c|c|c|c|c|c|}
\hline & Regions & Villages & $\begin{array}{l}\text { Male } \\
\text { FGD }\end{array}$ & $\begin{array}{l}\text { Female } \\
\text { FGD }\end{array}$ & $\begin{array}{l}\text { ADP-dominated } \\
\text { villages }^{1}\end{array}$ & $\begin{array}{l}\text { Manual labor- } \\
\text { dominated } \\
\text { villages }^{2}\end{array}$ & $\begin{array}{l}\text { Total FGDs } \\
\text { (average } \\
\text { participants) }\end{array}$ & $\begin{array}{l}\text { Total } \\
\text { participants }\end{array}$ \\
\hline Benin & $\mathrm{ADH} 2, \mathrm{ADH} 3, \mathrm{ADH} 4$ & 23 & 23 & 20 & 29 & 14 & $43(10)$ & 430 \\
\hline Kenya & $\begin{array}{c}\text { Narok, Kisumu, Nakuru, Bungoma, } \\
\text { Uasin-Gishu, Migori, Kirinyaga }\end{array}$ & 9 & 6 & 4 & 0 & 10 & $10(10)$ & 106 \\
\hline Mali & Koulikoro, Segou, Sikasso & 33 & 29 & 18 & 17 & 30 & $47(10-12)$ & ca. 500 \\
\hline Nigeria & Kaduna, Niger, Oyo & 22 & 15 & 14 & 7 & 22 & $29(10)$ & 294 \\
\hline Total & 16 & 87 & 73 & 57 & 53 & 78 & 129 & ca. 1330 \\
\hline
\end{tabular}

${ }^{1}$ Estimated share of farmers using animal draught power (ADP) for at least one farming step above $50 \%$

${ }^{2}$ Estimated share of farmers using animal draught power (ADP) for at least one farming step below $50 \%$. Estimates shares of ADP use are based on the average estimate of all participants of all FGDs in the respective village

\section{Research countries, sampling, and methods}

\subsection{Research countries}

This research was conducted in Benin, Kenya, Mali, and Nigeria under the research project "Program of Accompanying Research for Agricultural Innovation" (PARI), which operates in 14 African countries. ${ }^{1}$ The four case study countries were chosen to represent both West and East African countries and to reflect different smallholder farming systems (agro-pastoral, cereal-root crop mixed, maize mixed, root crops), socioeconomic characteristics, and levels of mechanization (see Table 1).

\subsection{Sampling and study sites}

The villages for the focus group discussions (FGDs) were sampled following a two-stage random sampling strategy. The sampling was determined by a complementary survey on the economics of state-led and market-led mechanization. For this, lists of beneficiaries of government programs distributing tractors across the four countries were obtained. In the first step, three regions (six districts in Kenya) were randomly sampled. ${ }^{2}$ Within these regions (districts), 150 beneficiaries of tractors were randomly selected under the condition that the communities of the beneficiaries were home to owners of privately purchased tractors of similar age. This procedure resulted in lists of locations in the selected regions (districts) with each at least two tractor owners: one who received a tractor from a government program and one who bought the tractor via the market. Thus, FGDs were held only in areas where

\footnotetext{
${ }^{1}$ See https://research4agrinnovation.org/
}

mechanization, in particular in the form of tractors, takes place and where villagers are therefore experienced with mechanization. A sub-set of these locations was chosen randomly for the FGDs. In each of these villages, lists of villagers were generated and participants for the FGDs were randomly selected. Table 2 provides an overview of the FGD conducted in the four countries, and Fig. 2 visualizes the selected sampling sites and their respective farming system. The FGDs were conducted between January and October 2019.

\subsection{Method: participatory impact diagrams}

The FGDs were structured using an innovative qualitative approach called participatory impact diagrams (PID), which is inspired by the idea of Mind-Maps and the Participatory Rural Appraisal approach. PID or similar approaches were used, for example, by Douthwaite et al. (2007) to assess the impact pathways of an integrated weed management project in Nigeria and by Kariuki and Njuki (2013) to evaluate a community development project in Kenya. PID allow examining both positive and negative effects related to the introduction of new policies and programs or new technologies as experienced by community members themselves. PID capture both direct and indirect effects. As suggested by Kariuki and Njuki (2013), the mapping was done separately for men and women to ensure both genders felt free to talk openly, and also to capture gender differences.

The actual focus group discussion with the PID went as follows: In the beginning, the facilitator asked some general questions to the communities such as how many

\footnotetext{
${ }^{2}$ Some regions in Northern Mali, Northern Nigeria, and Northern Kenya had to be excluded due to security concerns.
} 
Fig. 1 Farm tractors are on the verge to replace hand hoes across Africa (@Thomas Daum and Hannes Buchwald)
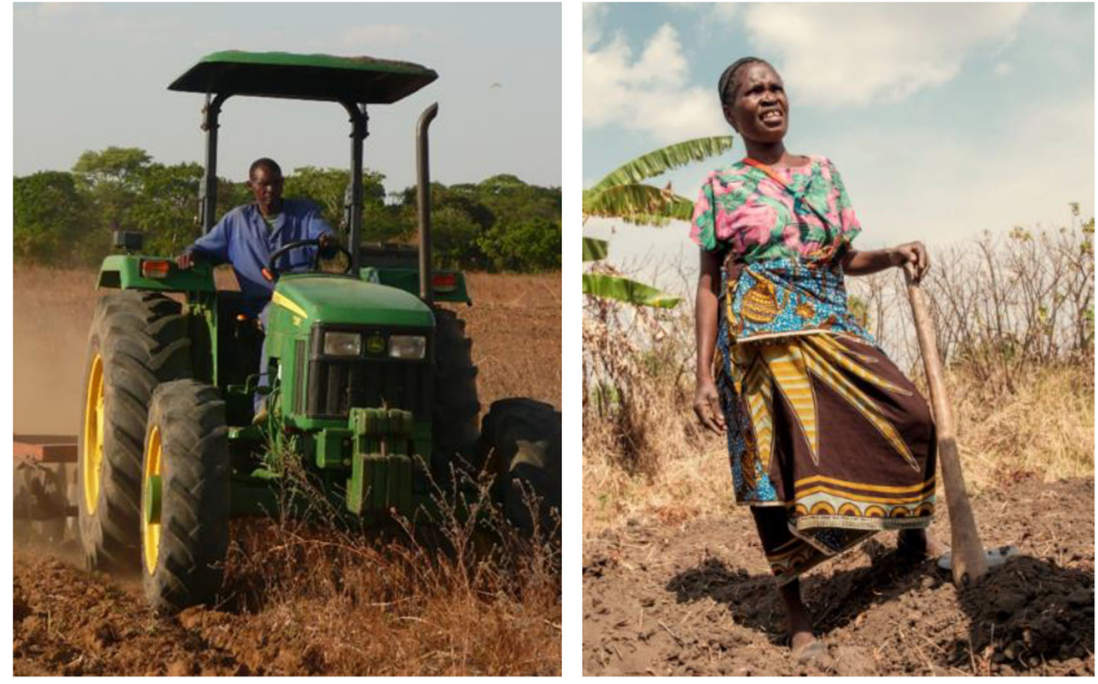

farm households live there and how many use manual, animal, and mechanical traction. Then, all participants introduced themselves and said how much land they cultivate and if they use manual, animal, and mechanical traction. After this introduction, the actual PID were drawn. For this, the facilitator drew a tractor on a large sheet of paper to represent agricultural mechanization. The sheet was divided into two halves: on the right, positive impacts were noted, and on the left, negative impacts were written down.

Participants were asked to mention both positive direct changes related to mechanization, and the facilitator drew the mentioned change on the paper (to the extent possible with simple illustrations). Participants were encouraged to discuss the mechanisms of the change and to assess whether the change affected mostly men or women. In Benin, Kenya, and Nigeria, it was also asked how many participants of the FGD have experienced or agree with this change. Once the direct impact was discussed, the facilitator asked for second-round effects or subsequent change of the direct changes, leading to the emergence of causal impact chains or the so-called change trees (see also Figs. 1 and 2 for example of actual PID). After discussing the different direct and indirect positive changes, negative aspects were discussed, following the same procedure. At the end of the session, the findings and, in particular, the drawn diagram were cross-checked with participants.

\subsection{Quality assurance}

To ensure scientific rigor and transparency during data collection and analysis, this study applied the standards of qualitative research recommended by Bitsch (2005). Since the FGDs could reveal sensitive topics, they were conducted in neutral environments. In particular, tractor service providers (or their close family) were excluded so that participants could freely discuss, without, for example, the need to fear not being served during the subsequent farming season. Also, governmental officials including extension workers were excluded. FGDs were conducted separately with female and male participants. Before every discussion, it was emphasized that participants should be honest in responding; in particular, that they should feel free to report also negative effects of mechanization. It was made clear that the discussions are related to a research project that will not lead to the provision of tractors to the village.

The facilitators were instructed not to propose or suggest possible impacts to avoid any influence on the discussion. The role of the facilitators was merely to structure the discussion and to ask follow-up questions on already identified impacts. Besides, the facilitators helped

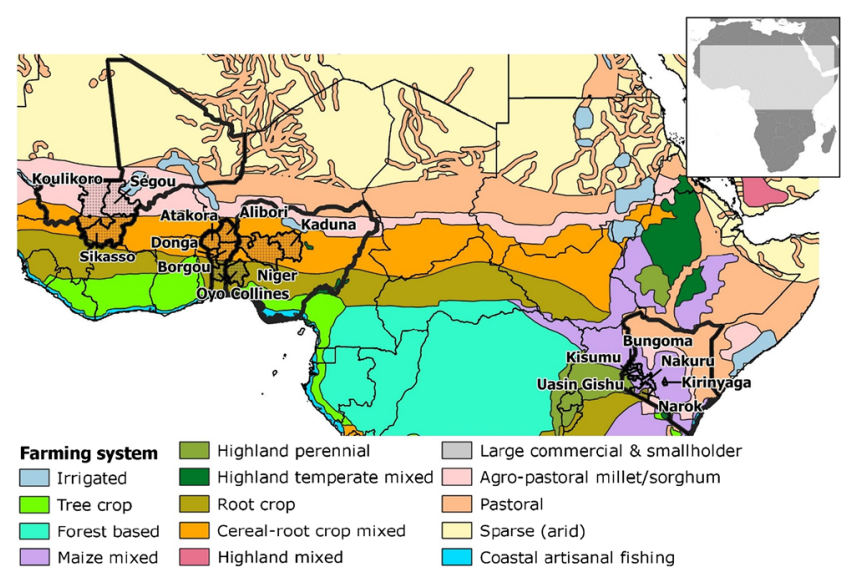

Fig. 2 Study areas and farming systems. Source: Sarah Graf. Administrative areas from the GADM database on Global Administrative Areas; farming systems from www.fao.org/geonetwork/ srv/en/main.home 
to encourage shy participants to speak and at times to curtail dominant speakers to give space to others. All the discussions were recorded, and the paper-based drawings were digitalized. Given the large number of FGDs, we can be reasonably confident that a point of saturation was reached (persistent observations, as suggested by Bitsch 2005). Also, emerging findings were discussed with research peers and experts at the local, national, and international levels (peer debriefing and member checks, as suggested by Bitsch 2005). In each research area, additional stakeholder interviews, for example with extension officers and experts from the local branch of the agricultural ministries, were conducted to triangulate the data, thus ensuring credibility and confirmability of the results.

\section{Results and discussion}

In the following section, three participatory impact diagrams are presented in detail to illustrate the type of results obtained (see Section 3.1). In the subsequent sections, positive (see Section 3.2) and negative effects (see Section 3.3) of mechanization will be discussed at a more aggregated level, summarizing results from all the FGDs conducted.

\subsection{Illustrative participatory impact diagrams}

Figure 3 shows exemplary diagrams representing three actual PID, with pictures added for illustration: Fig. 3 a shows a diagram drawn in an FGD consisting of nine men in rural Kenya, Fig. 3 b shows a diagram drawn with 12 women in Nigeria, and Fig. $3 \mathrm{c}$ shows a diagram from the same Nigerian village drawn with 15 men. Figure 3 a shows that all (nine out of nine) participants reported that mechanization allows farmers to cultivate more land - and this at a lower cost per hectare - which raises their income. Households use additional income for better diets, pay school fees, and diversify their farms. Three out of the nine participants reported that they are now able to spend more time on leisure. All participants reported that, as farmers now cultivate more land, they require more hired laborers for not yet mechanized activities such as weeding and harvesting, thereby creating employment. Also, they reported that the deep plowing associated with mechanization initially increases yields. However, this eventually destroys the topsoil, in particular when the disc plow is used, and leads to lower yields in the long term, as noted by six out of the nine participants on the negative side. Four out of nine participants discussed that the increase in leisure time is associated with "bad" leisure and a waste of money - in some cases, farmers thus lack money to buy the inputs needed for the subsequent farming season. Discussants also mentioned that mechanization leads to disputes over land and the cutting of trees on fields.

Figure $3 \mathrm{~b}$ shows findings from an FGD with women in Nigeria. Similar to the example from Kenya, they report farmland expansion and an increase in yields leading to additional income. All participants reported that mechanization reduces their workload and frees up time, which everyone but one woman use for more leisure. Reportedly, this aids participants in achieving better health. On the negative side, women reported that the area expansion that is triggered by mechanization leads to deforestation and that subsequently, it is more difficult to gather firewood. The increase in farmland reportedly leads to a reduction of grazing land and consequently underfed cattle. Nine out of twelve women mentioned that mechanization, in particular the use of the disc plow, causes soil erosion.

Figure $3 \mathrm{c}$ shows findings from an FGD conducted with men from the same village, highlighting both similarities and differences across gender. Similar to their female counterparts, men notice farmland expansion and yield effects, leading to higher incomes. Similar to women, men report that money is used to buy cattle as well as for education and housing, yet they also reported buying luxury items and obtaining second wives (as compared to clothes and travel, which are mentioned by women but not men). Unlike in the female FGD, men report that more food is available as a consequence of mechanization. While men also report a lower workload for activities on the field, they do not report an increase in resting time. Men do not report deforestation as a negative effectand subsequently, the decline in firewood is not noted. As women, they report a decline in grazing land. Also, they report that cattle routes are encroached on, leading to conflicts with pastoralists. Like women, men report soil erosion effects; however, they expand the impact chain with a decline in soil fertility and yields and, subsequently, a decline in the "useful" life of the land. Men highlight that mechanized farmers use more herbicides since controlling weeds on the increased acreage is no longer feasible by hand.

\subsection{Positive impacts}

\subsubsection{Agronomic and environmental impacts}

Figures 4, 5, 7, and 8 show perceptions of positive and negative agronomic and environmental as well as socioeconomic effects of farm mechanization, showing both the share of FGDs and individuals identifying impacts. Perceptions are reported separately for male and female respondents. The share of FGDs is reported for all countries. The share of individuals is reported for all countries except Mali where this information was not collected. Each of the figures shows the twelve most frequently mentioned effects. In the supplementary materials (Figures S1-4), additional effects are presented. 
Fig. 3 Participatory impact diagrams (PID). a) PID with men in one Kenyan village; b) PID with women in one Nigerian village; c) PID with men in the same Nigerian village as b). Source: FGDs, authors a

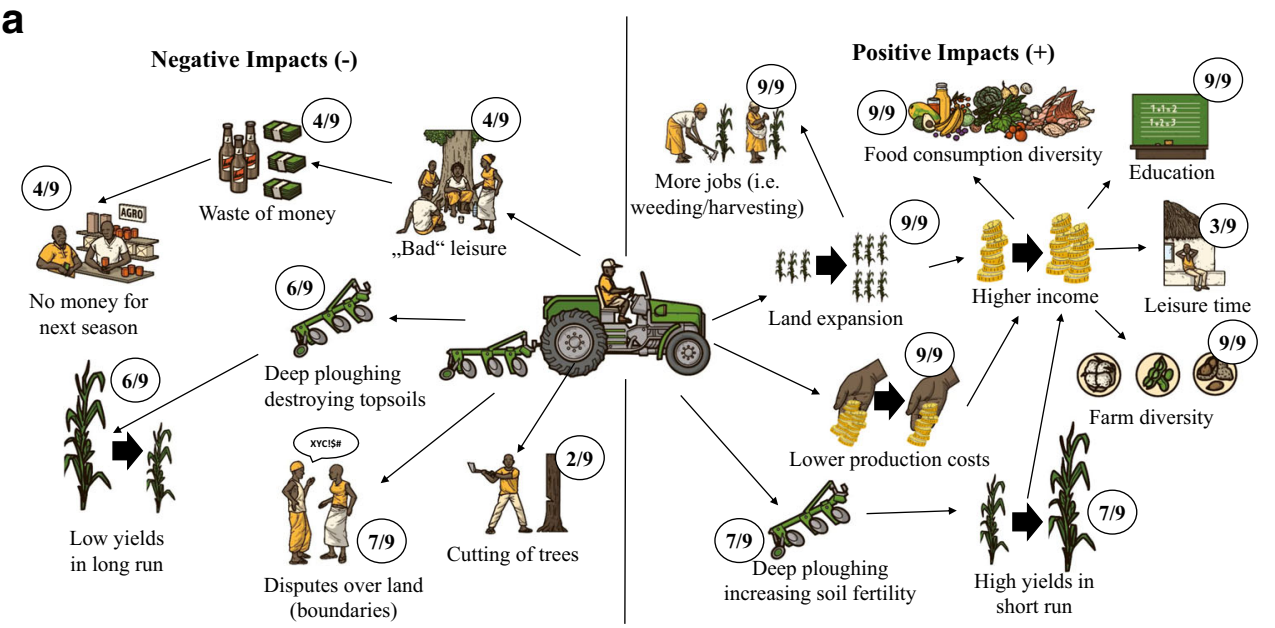

b

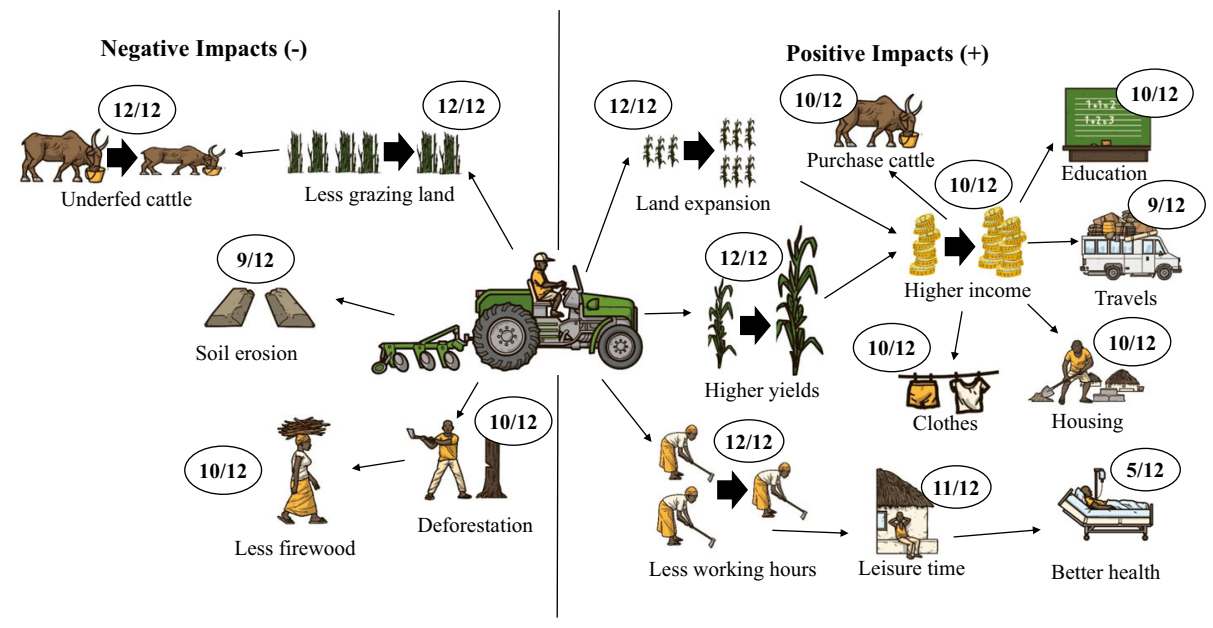

C

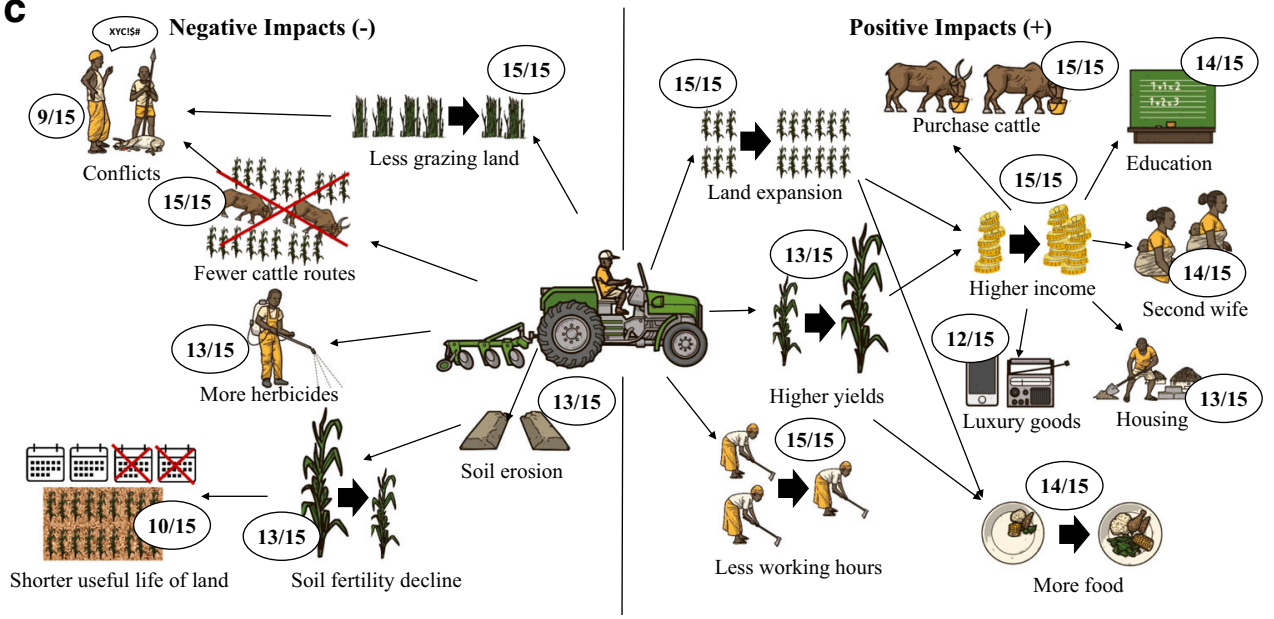

In the supplementary materials, the results are also shown separately for communities dominated by animal traction and communities dominated by hand hoes. In general, there were no notable differences in perceived effects between systems dominated by hand hoes and systems dominated by animal traction, and such differences will be highlighted in the text.
Figure 4 shows perceptions of positive agronomic and environmental effects across the four countries; the most often mentioned positive effect was an increase in yields (reported in $72 \%$ of all FGDs), which was attributed to mechanization improving the timeliness of farming, making it possible to complete operations at the best time, reducing weed pressure 


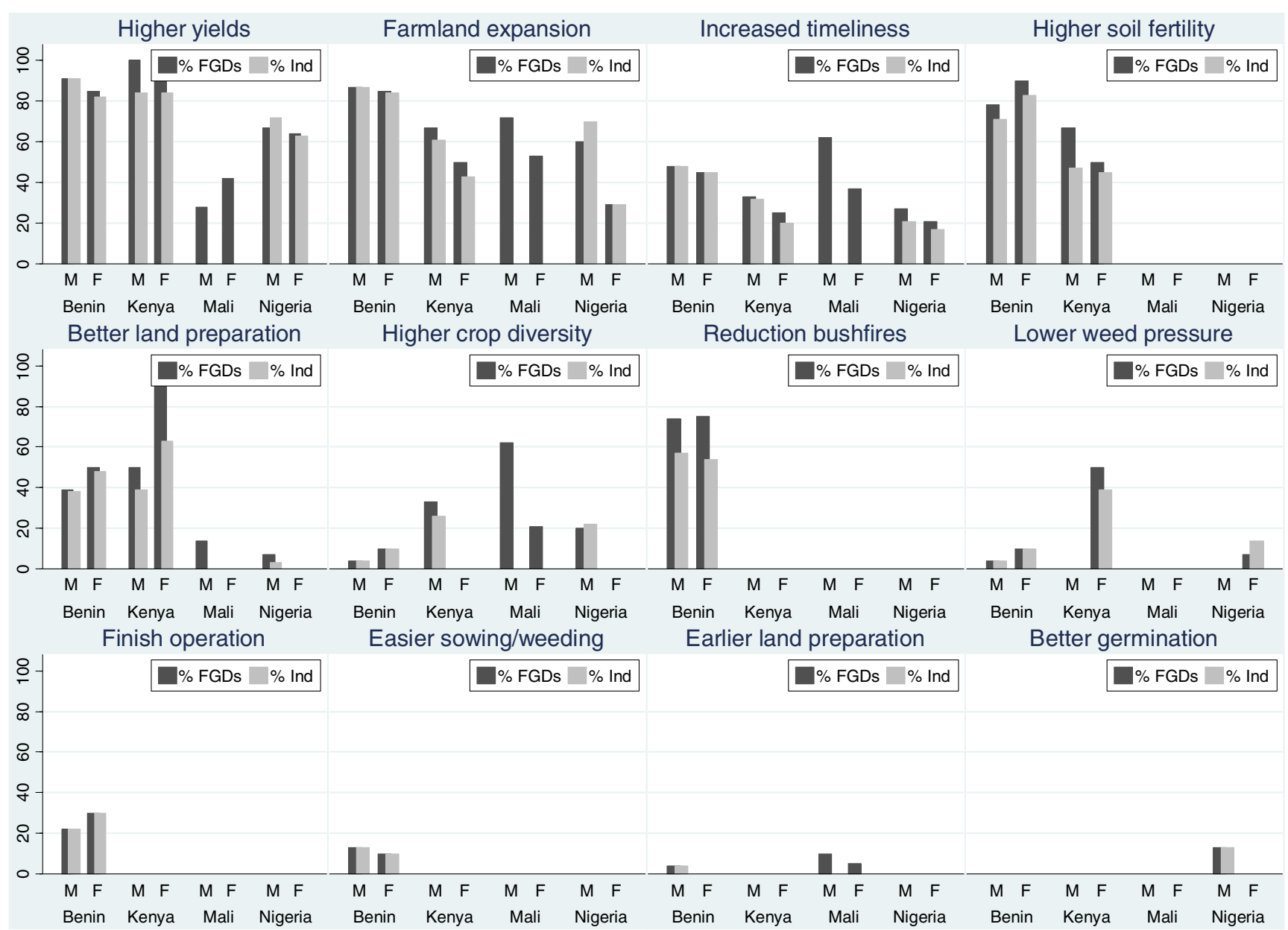

Fig. 4 Perceptions of positive agronomic and environmental impacts of agricultural mechanization. Percentage share of focus group discussions (FGDs) and individuals (Ind) identifying positive agronomic and environmental impacts of the use of tractors during land preparation by gender (M, male; F, Female). "Finish operation" refers to being guaranteed to finish the operation in time, which is enabled by a

quicker completion of tasks and a lower reliance on manual labor. "Easier sowing/weeding" was attributed to better and more uniform land preparation. "Earlier land preparation" was mentioned because it allows the cultivation of dry soil. "Better germination" was attributed to better seedbed preparation. The twelve most frequent effects are shown, and additional effects are shown in $\mathrm{S} 1$

by better weed burial, and enhancing the quality of land preparation, for example, enabling better seedbed preparation. ${ }^{3}$ This reflects findings from Adu-Baffour et al. (2019) in Zambia, Mano et al. (2020) in Cote d'Ivoire, and Silva et al. (2019) in Ethiopia, among others, and is illustrated by the following quote:

"When (...) using tractors, we are able to incorporate weeds easily and this increases soil fertility unlike preparation by hand where we remove the weeds and pile them on the sides" (FGD, Kenya)

Another major positive effect identified was the expansion of the land size that farm households cultivate (reported in $61 \%$ of all FGDs). Using hand tools, the amount of land

\footnotetext{
${ }_{3}^{3}$ Farmers also reported that agricultural mechanization increases soil fertility in $36 \%$ of all FGDs.
}

cultivatable per household is limited by labor constraints, either related to family or hired labor. Using tractors, more land can be cultivated, which, together with the increase in yields, helps farmers to increase agricultural production. This confirms findings from Adu-Baffour et al. (2019) in Zambia, Houssou and Chapoto (2015) in Ghana, Kirui (2019) in twelve African countries, and Takeshima et al. (2013) in Nigeria, among others, and is illustrated in the following quote:

"Many farmers have land that they can't farm, it is let as fallow. With the tractor, the land is farmed and produces volumes of crops beyond the consumption capacity of the household" (FGD, Mali)

There are additional positive agronomic impacts. Reportedly, mechanization allows farmers to grow a 


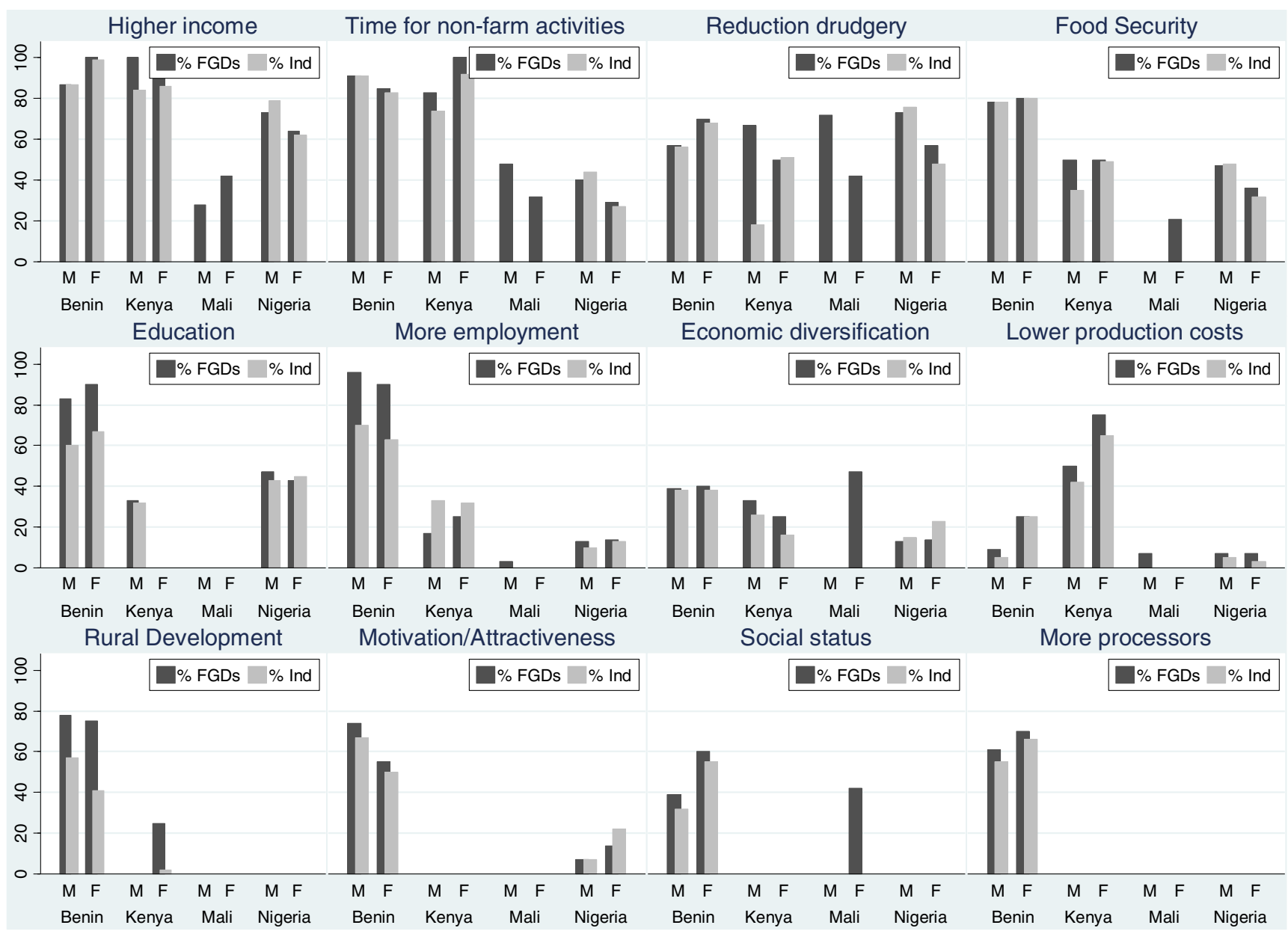

Fig. 5 Perceptions of positive socioeconomic impacts of agricultural mechanization. Percentage share of focus group discussions (FGDs) and individuals (Ind) identifying positive socioeconomic impacts of the use of tractors during land preparation by gender (M, male; F, Female). "Reduction of drudgery" refers to the physical intensity of work.

larger diversity of crops since they can cultivate more land and have more time, an observation shared in $19 \%$ of all FGDs, which may have implications for food and nutrition security (see also Sibhatu and Qaim 2018). Interestingly, this was reported in $30 \%$ of all male FGDs but only $8 \%$ of all female FGDs. Similarly, gender seems to play a role in the perceived effects on weeds: $17 \%$ of all female FGDs reported a lower weed pressure but only $1 \%$ of all male FGDs, potentially because women are often responsible for weeding. This contradicts Baudron et al. (2019) finding that eight East African study sites are "not as dominated by female labor as commonly thought" (p.9). While many impacts are reported across several countries, some are not. For example, the observation that using tractors led to a reduction of the use of bushfires for land clearing,

\footnotetext{
${ }^{4}$ Other factors explaining the higher food and nutrition security are the higher levels of agricultural production and farm diversity.
}

"Education" was attributed to having more money and time. "Market access" was attributed to the possibility to use tractors for transportation. The twelve most frequent effects are shown, and additional effects are shown in S2

which is reportedly better for soil fertility, was only reported in Benin (in $73 \%$ of all FGDs).

\subsubsection{Socioeconomic impacts}

Figure 5 shows that the positive agronomics effects related to agricultural mechanization translate to positive socioeconomic effects. The most frequently mentioned positive effect perceived was an increase in financial security and income (reported in $74 \%$ of all FGDs), confirming Adu-Baffour et al. (2019), among others. The additional income is used to buy more, and more diverse food, as noted in $45 \%$ of all FGDs ${ }^{4}$ and to pay education expenditures, as reported in $37 \%$ of all FGDs, reflecting Adu-Baffour et al. (2019). Also, money is used, for example, for religious activities and travels (such the haj in Nigeria) as well as for obtaining second wives and for "bad leisure" (as visible in the diagram from Kenya, see Fig. 1). Some participants reported that the increase in income gives them financial autonomy and the ability to cope with the 


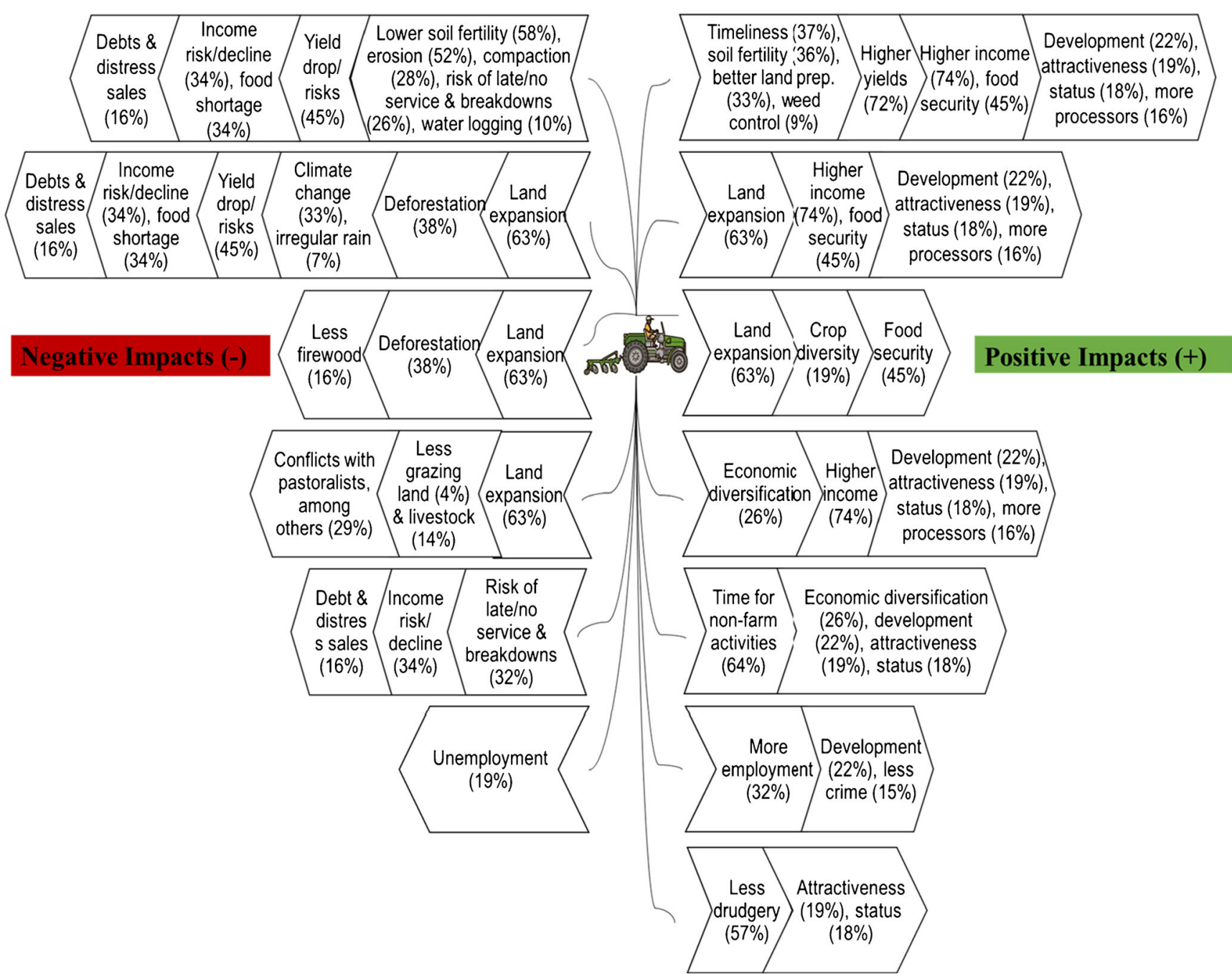

Fig. 6 Selected perceived causal chains on the perceived negative and positive impacts of farm mechanization. Source: FGDs, authors. Percentages indicate how frequently effects were mentioned in the FGDs. Only effects mentioned at least at $5 \%$ of all FGDs are included

various risks associated with agricultural production. Other major perceived benefits are to have more time for non-farm activities such as resting, family, education, and off-farm work (reported by $57 \%$ of all FGDs).

Figure 6 shows some typical perceived causal impact chains of mechanization, as identified in the FGDs. The figure shows that there are different pathways and that small intermediate effects can aggregate into a larger subsequent effect. Regarding income effects, the main drivers are higher yields and area expansion (see also Adu-Baffour et al. 2019; Kirui 2019). An additional reason is an economic diversification. With mechanization, households have more time to pursue non-agricultural businesses and may have the capital to start non-agricultural businesses. Moreover, in $32 \%$ of all FGDs, participants perceived that mechanization generates rural employment. One reason is that mechanization can lead to higher yields and cropland expansion, which reportedly leads to a higher labor demand during subsequent farming steps, such as weeding, harvesting, and processing. In Benin, for example, respondents perceived that this has led to a larger number of processers (mentioned in 65\% of the FGDs). This confirms Binswanger (1986) showing how the difference in frame conditions can explain diverse employment effects related to mechanization. This mechanism is also illustrated in the following quote:

"Indeed, the tractor makes it possible to increase the size of the plantings. This increase generates a higher demand in terms of manpower to carry out operations not yet mechanized" (FGD, Mali)

Moreover, there are positive spillovers from the overall rising rural wealth on employment - confirming the potential of prospering farmers to drive the rural economy (Hazell et al. 2010). For example, participants reported that many mechanized farmers consume more and start non-agricultural 


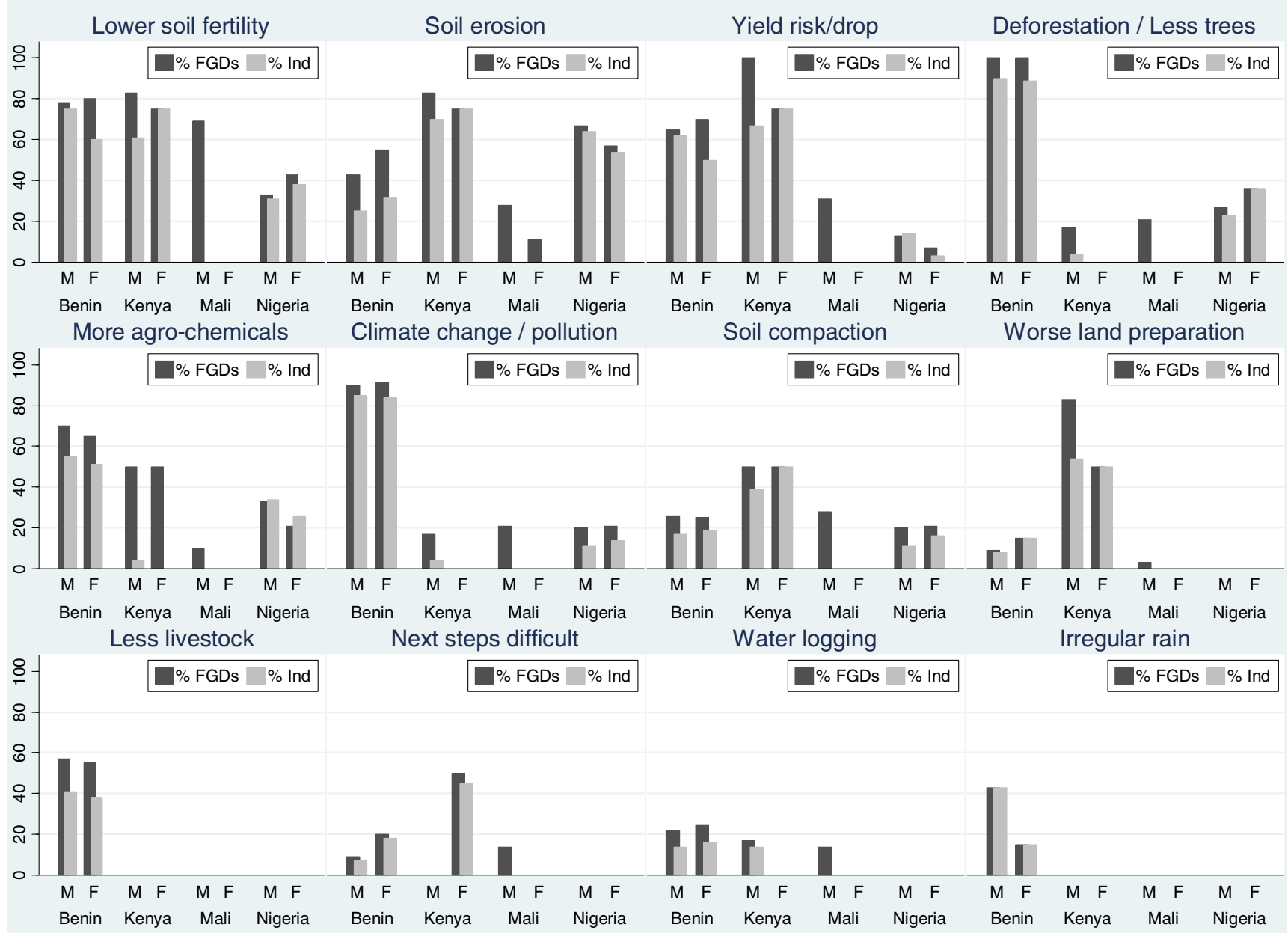

Fig. 7 Perceptions of negative agronomic and environmental impacts of agricultural mechanization. Percentage share of focus group discussions (FGDs) and individuals (Ind) identifying negative agronomic and environmental impacts of the use of tractors during land preparation by

businesses. It was also noted that mechanization creates jobs for tractor operators and technicians. All of these aspects contribute to the perception that mechanization drives rural development, as noted in $22 \%$ of FGDs. Employment opportunities and rural development reportedly reduce the incidence of crimes and violence in the villages, as noted in $15 \%$ of all FGDs.

"The possibility of driving a tractor and providing services to earn money is a source of motivation for young people. (...) We are witnessing an increase in the number of tractor drivers, a reduction of the rural exodus by young men, an increase in income, a better social consideration, and a reduction of insecurity (e.g., theft)" (FGD, Benin)

In $57 \%$ of all FGDs, villagers reported that mechanization is associated with a reduction in drudgery, that is the physical gender (M, male; F, Female). "More agro-chemicals" was attributed to the land expansion effects and the need to counterbalance a decline in soil fertility. The twelve most frequent effects are shown, and additional effects are shown in $\mathrm{S} 3$

intensity of work, which is reportedly good for health and - together with the higher income associates with the use of tractors - helps to increase the motivation and attractiveness related to farming (as reported in 19\% of all FGDs), confirming Sims and Kienzle (2016). In Nigeria, this was also perceived to encourage women to farm by female respondents (mentioned in $21 \%$ of the female FGDs). In $18 \%$ of all FGDs, participants mentioned a higher status related to the use of "modern" tractors as compared to animal traction and "backward" hand hoes. Interestingly, if female farmers have access to mechanization, it can greatly empower them as mechanized households enjoy a higher social status, a fact that was reported in particular by women (in 27\% of all female FGDs as compared to $10 \%$ of all male FGDs). In Mali, in particular, women also perceived benefits from a lower reliance on male labor when using tractors (reported in $21 \%$ of all female FGDs). 


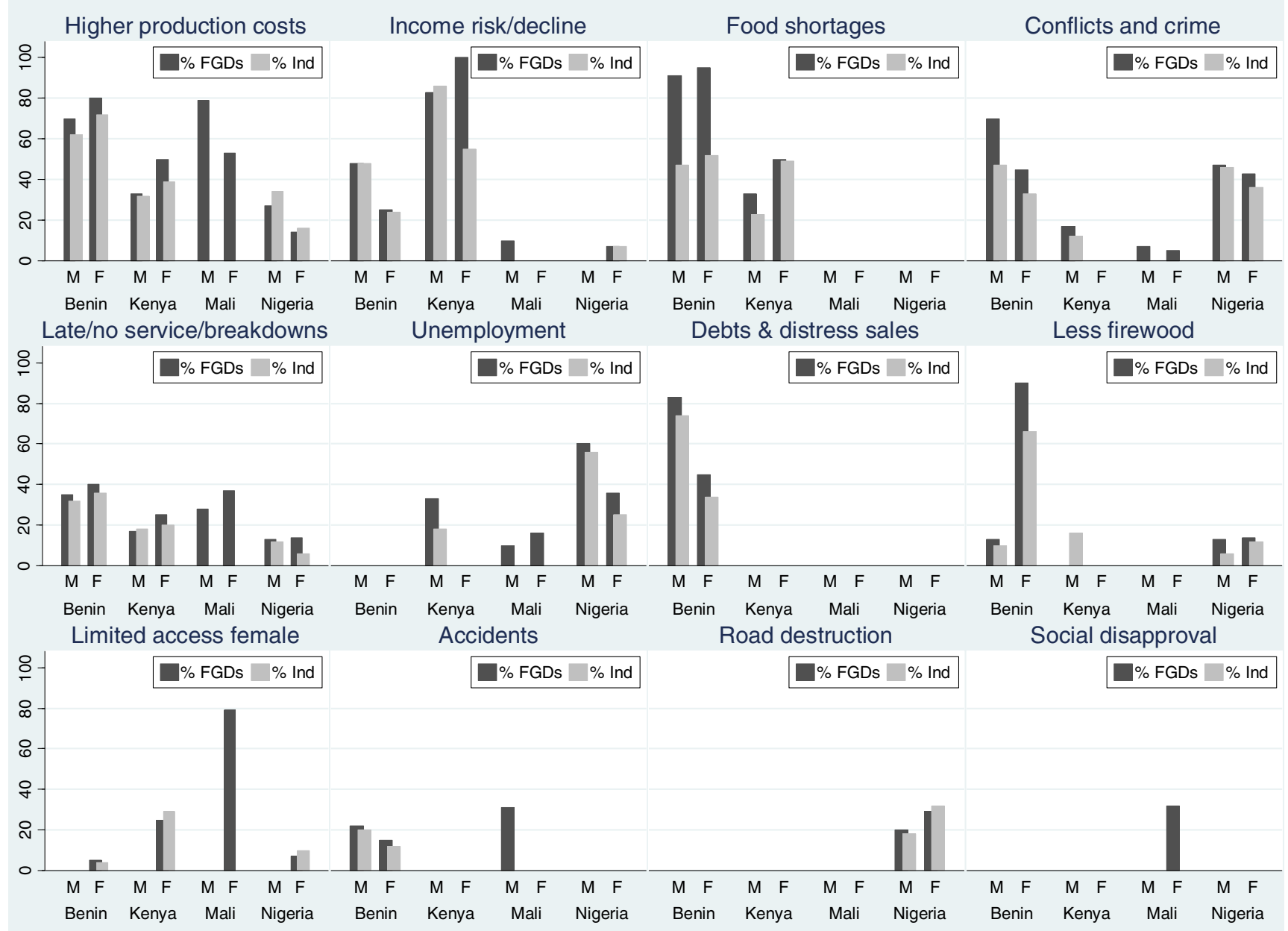

Fig. 8 Perceptions of negative socioeconomic impacts of agricultural mechanization. Percentage share of focus group discussions (FGDs) and individuals (Ind) identifying negative socioeconomic impacts of the use of tractors during land preparation by gender (M, male; F, Female).
"Road destruction" was attributed to tractors leaving ruts on roads in the rainy seasons. The twelve most frequent effects are shown, and additional effects are shown in $\mathrm{S} 3$

\subsection{Negative impacts}

\subsubsection{Agronomic and environmental impacts}

Participants also perceived negative effects related to mechanization, comprising both agronomic and environmental effects (see Fig. 7) and socioeconomic effects (see Fig. 8). Figure 5 shows some selected causal chains as identified by respondents themselves explaining these negative outcomes of mechanization. In $58 \%$ of all FGDs, participants noted that, while mechanization increases soil fertility in the short term, it leads to a decline in soil fertility in the long term, in particular when the disc plow is used (confirming, among others, Benin 2015). This was mainly attributed to mechanization triggering soil erosion (reported in $52 \%$ of all FGDs) and causing compaction due to the use of heavy tractors (reported in 28\% of all FGDs), confirming Sims and Kienzle (2016) who warn that inappropriate mechanization can accelerate soil erosion and compaction. This was related to the destruction of soil structures and the creation of impermeable plowpans that leave soils vulnerable to rain and wind erosion (see also Sims and Kienzle 2017). In addition to making soils susceptible to erosion, these plow-pans and soil compaction can also cause waterlogging, as noted by Sims and Kienzle (2017) and illustrated in the following quote as noted in Benin:

"The introduction of the tractor increases soil compaction given the weight of the tractor and accessories. (...) This is followed by the problems of flooding and erosion, which considerably reduce the fertility of the areas cultivated and consequently the yield" (FGD, Benin) 
These negative aspects of mechanized tillage on soils explain the observation that mechanization can lead to lower yields in the long term, which was mentioned in $45 \%$ of all FGDs. However, there are additional reasons for lower yield and higher yield risks, including the risk of late or no service delivery (reported by $26 \%$ of all FGDs, see Section 3.3.2) and worse land preparation ${ }^{5}$ (see also Daum and Birner 2017 for Ghana and Adu-Baffour et al. 2019 for Zambia). In Kenya, some farmers also complained that migratory tractor service providers facilitate the spread of weeds across different agroecological zones as the following quote illustrates:

"Use of tractors has led to introduction of a new type of weed called 'arap misoi' [Guitaria Abysinica, explanation added], which causes low yields to our wheat crop" (FGD, Kenya)

While some effects are only affecting individual farms, others have more far-reaching effects. The results suggest that mechanization is associated with area expansion, as reported in $38 \%$ of all FGDs, which was seen as positive by the respondents since it helps to increase agricultural production and income (see Section 3.2). However, it is also concerning from an environmental perspective, since it is associated with largescale deforestation, as also noted by the respondents, in particular in Mali and Nigeria where forest covers are still relatively high, albeit declining fast (see Table 1). This confirms Sims and Kienzle's (2016) warning that inappropriate mechanization can cause forest and rangeland destruction. Moreover, $43 \%$ of all male farmers in Benin noted that deforestation leads to more irregular rainfall, which increases yield risks and has reportedly triggered desertification in some areas. In 33\% of all FGDs, respondents perceived mechanization to contribute to climate change due to its exhausts and deforestation.

Mechanization not only reportedly leads to deforestation but also causes the clearing of trees from the fields to facilitate tractor operation, which reportedly reduces biodiversity and makes the soil more susceptible to rain and wind erosion, as the following quote illustrates:

"Tractor plowing requires land without obstacles. Therefore, trees are destroyed to enable the tractor to work comfortably. This exposes the land." (FGD, Mali)

This can have negative agronomic and environmental effects, as well as nutritional consequences when farmers destroy fruit trees to ensure mechanization (see Kansanga et al. 2019 for Ghana).

\footnotetext{
${ }^{5}$ For example due to a wrong plowing depth and a bad burial of weeds.
}

\subsubsection{Socioeconomic impacts}

As shown in the previous section, mechanization can lead to yield risks and decline (reported by $45 \%$ of all FGDs). Consequently, participants in $34 \%$ of all FGDs reported that mechanization can lead to income risks and decline. The higher risk associated with mechanization becomes problematic in combination with one other effect: in $51 \%$ of all FGDs, participants mentioned that mechanization increases the production costs of farming. ${ }^{6}$ Thus, both the likelihood and severity of negative effects increase, which has led to cases of indebtedness and distress sales of livestock, machinery, and land (reported in $16 \%$ of all FGDs). In $34 \%$ of all FGDs, participants discussed that the different risks associated with mechanization can lead to food shortages. Yet, while this aspect was reported across many FGDs, the share of individuals identifying this aspect is much lower (see Fig. 8). Risks affect not only service receivers but also tractor owners who suffer economically from frequent tractor breakdowns.

Another major concern related to mechanization is that it may create unemployment. This was mentioned in 19\% of all FGDs. However, numbers vary starkly across the countries, confirming Binswanger (1986) who showed that employment effects differ depending on the frame conditions, for example, the possibility for land expansion. In Benin, where mechanization was most frequently associated with area expansion, unemployment effects were reported in none of the FGDs; in densely populated Nigeria, where fewer people reported land expansion, unemployment effects were reported by $48 \%$ of FGDs. Unemployment effects are illustrated in the following quote:

"With the tractor, many laborers remain unemployed and move to urban areas" (FGD, Mali)

Unemployment effects are in particular related to the land preparation period since mainly tillage is mechanized (see Table 1). In some areas, mechanization is mostly associated with a shift in labor demand from the beginning towards the end of the farming season, a pattern that was also observed by Adu-Baffour et al. (2019). Reportedly, this is problematic in cases where rural laborers need the income from wage labor at the beginning of the season to purchase inputs for their fields.

Across the four countries, participants felt that mechanization can lead to social tensions, conflicts, and crime, aspects noted in $29 \%$ of all FGDs. One reason for conflicts is a clash between farmers and tractor owners if service provision is done too late, too badly, or not at all, all of which can lead

\footnotetext{
${ }^{6}$ On the other hand, others noted that mechanization can contribute to decrease the risks, since it enhances the timeliness of farming and helps households to build up capital for bad times, to diversify crop production, and to pursue income-generating activities.
} 
to large yield drops, as noted above. Conflict also occurs between different crop farmers over who has access to mechanization services and between tractor owners over the fuel needed to run the tractors. These conflicts can be violent, in particular, if they are related to land issues. Land conflicts were perceived to be increasingly common due to the farmland expansion effects of mechanization (confirming Kansanga et al. 2018b for Ghana). Such conflicts can also pitch crop farmers against pastoralists whose grazing lands are increasingly encroached upon, as mentioned in $4 \%$ of all FGD (but $17 \%$ in Nigeria) (see Fig. 7). Social conflicts also spark over accidents injuring tractor operators or villagers and may require expensive health care.

As with most new technologies, mechanization leads to benefits for some but not for others. The role of rural labor has been discussed above. Also, the rise of tractors has led to less demand for providers of animal draught services, although the number of FGDs reporting this is surprisingly low (reported by 3\% of all FGDs and 7\% of all FGDs in systems dominated by animal traction). While other studies have found that smallholder farmers often have worse access to mechanization (Daum and Birner 2017 for Ghana), this aspect was also surprisingly absent from many FGDs - with $15 \%$ of all FGDs indicating this negative consequence. However, the risk of late service delivery (and dependency on tractor owners) frequently often reported to be higher for smallholder (and female) farmers who have a lower bargaining power compared to farmers with more land.

Overall, mechanization is less accessible for women compared to men, which may exacerbate existing gender inequalities (see also Fischer et al. 2018; van Eerdewijk and Danielsen 2015). Less access for women was reported in $29 \%$ of all female FGDs - as compared to $0 \%$ of the male FGDs. The reasons for lesser access of female farmers to mechanization are social norms as well as the fact that they often have smaller and more scattered plots compared to men (as also observed by Daum and Birner in Ghana). Such plots are less lucrative to service providers, as illustrated by the following quote from Benin:

"Service providers tend to prioritize men and large producers to provide services. Thus, women and smallholders are often marginalized" (FGD, Benin)

Also, women, who are mostly responsible for cooking, face disadvantages as mechanization destroys forests and reduces the amount of firewood available. Therefore, women need to spend more time and travel long distances to fetch firewood. This was reported in $26 \%$ of all female FGDs as compared to $7 \%$ of all male FGDs and reflects Lado (1992). Other effects mostly affect men, however. Yield risks associated with mechanization were reported in $52 \%$ of all male FGDs, but only $38 \%$ of all female
FGDs, perhaps because a higher share of male crops is mechanized. Accidents were reported in $13 \%$ of all male FGDs (compared to $4 \%$ of female FGDs), and unemployment effects were reported in $26 \%$ of all male FGDs (compared to $13 \%$ of female FGDs), potentially because most tractor operators and wage laborers are male. In $18 \%$ of all female FGDs, as compared to $6 \%$ of all male FGDs, respondents complained that mechanized land preparation raises the workload for not yet mechanized activities such as weeding and harvesting and processing. Differences in gender roles may explain why this effect is mainly felt by women. This contradicts Daum et al. (2020) and also Baudron et al. (2019) who found that mechanized tillage reduces women's labor burden since it can suppress weed growth.

\subsection{Implications and limitations}

\subsubsection{Tractors will change the face of African farming}

The results suggest that the use of tractors will change the face of African farming and rural areas through various - often intertwined-agronomic, environmental, and socioeconomic pathways. The diversity of perceived impacts across the study sites - with some effects mentioned across the study sites and others in only a few-suggests that some effects are ubiquitous but others are determined by variations in local agroecological and socioeconomic conditions such as crop and soil types, rainfall patterns, land availability, and rural wages as well as culture (such as social norms related to gender roles) and the policy framework. This makes it difficult to draw general conclusions on "the effects of mechanization" and calls for more applied agronomic, environmental, and socioeconomic research at the local level.

Perceptions on yield changes related to the use of tractors for land preparation were mixed, reflecting the current literature, which is characterized by some studies finding positive yield effects (Adu-Baffour et al. 2019; Mano et al. 2020), while others reporting mixed or no effects (Houssou and Chapoto 2015; Kirui 2019). Yield effects likely depend on agro-ecological conditions such as soil types and rainfall patterns and the use of complementary agronomic practices (Binswanger and Donovan 1987; Daum and Birner 2020; Mano et al. 2020). Adu-Baffour et al. (2019), Baudron et al. (2015), and Silva et al. (2019) suggest that farm mechanization can raise yields in smallholder farming systems where labor and not land limits production. Yield effects may vary over time; however, the rural residents reported that yields increase at first as mechanization helps to improve the timeliness and quality of land preparation (confirming Baudron et al. 2015; Silva et al. 2019). Initial yield effects may be reinforced as some newly mechanized farmers cultivate previously uncultivated and thus fertile land (Adu-Baffour et al. 2019). Yet, yields reportedly often drop after some years as current 
mechanization practices, in particular the use of the disc plow, lead to soil erosion and a decline in soil fertility (see also Benin 2015; Sims and Kienzle 2016).

According to the perceptions from the four countries, mechanization during land preparation has mixed effects on employment, again confirming the literature (AduBaffour et al. 2019; Binswanger 1986; Cossar 2019; Houssou and Chapoto 2015; Kirui 2019; Mano et al. 2020). In some areas, mechanization reduces the demand for labor, including both family labor, which is positive, and also hired labor, which can be problematic (see also Baudron et al. 2019). However, in areas where farmers reported cropland expansion, mechanization seems to create rather than destroy rural jobs. This pattern was predicted by Binswanger (1986) based on economic theory and observed in practice by Adu-Baffour et al. (2019) in Zambia, among others. In this study, in Benin, which has the highest share of respondents from all countries reporting land expansion, none reported unemployment effects. It is important to emphasize that the employment effects reported in this paper refer to the mechanization of land preparation and that the mechanization of different tasks has different implications for employment, which calls for more empirical research (see also Daum and Birner 2020).

The results reveal that mechanization has effects, other than on yield and labor. Regarding agronomic and environmental effects, mechanization is associated with the above-discussed soil fertility and erosion problems but also soil compaction and waterlogging (see also Sims and Kienzle 2016; Sims and Kienzle 2017). Moreover, mechanization contributes to the cutting of farm trees, which can have negative agronomic and environmental effects and has nutritional consequences when farmers destroy fruit trees (see also Kansanga et al. 2019). Another concern is that mechanization leads to monocultures of easy to mechanize crops, with negative effects for nature and human nutrition (Berhane et al. 2017; Kansanga et al. 2018). The results suggest that this is not the case. Respondents even reported that mechanization enhances crop diversity, mostly since farmers have more space for additional crops.

While some effects only affect individual farms, others have more far-reaching effects. The results suggest that mechanization is associated with area expansion, which was seen as positive by the respondents since it helps to increase agricultural production and income. However, it is concerning from an environmental perspective since it is associated with largescale deforestation. Area expansion effects are confirmed across Africa (Adu-Baffour et al. 2019; Houssou and Chapoto 2015; Kirui 2019; Takeshima et al. 2013). The conversion of forests and savannah to farmland can change the local climate, affect biodiversity, and lead to large greenhouse gas emissions (Searchinger et al. 2015).

While mechanization has various positive socioeconomic effects, there are also negative effects, many of which have been neglected. Risk is of particular importance here. On the one hand, mechanization contributes to decreasing the risks, since it enhances the timeliness of farming and helps households to build up capital for bad times, to diversify crop production, and to pursue income-generating activities. On the other hand, it increases risks by causing soil fertility declines and erosion as well as waterlogging, all of which can lead to large yield drops. Moreover, many mechanized farmers rely on tractor service providers, who do not always show up or come too late (see also Daum and Birner 2017). As the production costs of farming increase with mechanization, the severity of negative effects increases, which has led to cases of indebtedness due to mechanization.

As with most new technologies, mechanization leads to benefits for some but not for others. The role of rural labor has been discussed above. Also, since mechanized farmers cultivate more land, grazing land is increasingly encroached upon, leading to conflicts between crop farmers and pastoralists and between crop farmers themselves (confirming Kansanga et al. 2018b). While other studies found that smallholder farmers often have worse access to mechanization (see Daum and Birner 2017 for Ghana), this aspect was surprisingly absent from many FGDs.

Social norms seem to largely shape the extent to which women can benefit from mechanization. In Benin, $60 \%$ of all female FGDs perceived that the use of tractors is associated with higher social status (which was reported by only $39 \%$ of the male FGDs). In Mali, $21 \%$ of all female FGDs reported that mechanization can reduce the reliance on male laborers. These examples suggest that mechanization - if accessible - can empower female farmers. Yet, the results also showed that women have less access to mechanization compared to men, confirming Daum and Birner (2017) in Ghana, Fischer et al. (2018) in Tanzania, Kirui (2019) in twelve African countries, and van Eerdewijk and Danielsen (2015) in Kenya and Ethiopia. Under such conditions, mechanization may also "undermine women's position or exacerbate gender inequalities" (van Eerdewijk and Danielsen 2015, p.56). Yet, while gender inequalities related to the access to mechanization were reported in all countries, they were much more prominent in some countries such as Mali, where $71 \%$ of all female FGDs shared this perception than in others such as Benin, where only $5 \%$ of all female FGDs reported them.

\subsubsection{Targeted complementary policies are needed for sustainable mechanization}

Drawing on the perceptions of rural residents, this paper has revealed various agronomic, environmental, and socioeconomic effects of mechanization, many of which are shaped by variations in local agro-ecological and socioeconomic conditions (see also Section 3.4.1). As noted above, this makes it difficult to draw general conclusions on "the effects of mechanization." However, it can help to sensitize researchers and policymakers on which 
potential effects they should "have in the back of their mind" when planning and conducting applied research and designing and implementing policies at the local level.

While most of the perceived changes associated with farm mechanization were positive, the rural residents also mentioned negative effects of farm mechanization, in particular soil erosion, deforestation, land-use conflicts, gender inequalities, and risks. These effects are not inherent to farm mechanization and can be addressed with complementary agronomic practices and adequate policies. For example, soil erosion can be reduced with locally adapted Conservation Agriculture, which minimizes soil disturbance using rippers or direct seeders, protects soils with a continuous soil cover, and builds fertility with the help of crop residues and crop rotations using leguminous plants (Baudron et al. 2015; Jaleta et al. 2019; Sims and Kienzle 2017).

Similarly, deforestation and the conversion of savannah land can be minimized with careful land-use planning, for example, by protecting land that is particularly valuable for climate change mitigation, biodiversity, and wildlife (Daum and Birner 2020). Negative effects can also be minimized with mechanization strategies suitable for crop-livestock-forestry systems (as suggested by Alves et al. 2017). When trying to minimize the negative effects of mechanization, it is important to keep in mind that there is no environmental benefit in preventing small-scale farms from mechanizing if large-scale farms expand cultivation instead (Sulieman 2015). Land-use planning as well as land reforms improving tenure security can also mitigate conflicts between pastoralists and farmers and between farmers with rival claims over agricultural commons (Kansanga et al. 2018b). Scale appropriate mechanization, where "machines are adapted to farm size and not the opposite" (Baudron et al. 2019b, p.154), can reduce some of the potential environmental effects of mechanization as well as address social effects such as consolidation and labor displacement (Baudron et al. 2015; Baudron et al. 2019b).

Policies are also needed to ensure smallholder farmers can reap the benefits of agricultural mechanization. Supporting tractor hire markets with appropriate infrastructure and institutions, for example, can help to ensure smallholder farmers' access to mechanization (Daum and Birner 2017). Ensuring that women can benefit from mechanization is more "complex" (van Eerdewijk and Danielsen 2015, p.56). Entry points may comprise gender awareness campaigns (including "show-casing" women role models) and supporting women's mechanization groups and entrepreneurship with knowledge and skills development and access to finance, among others (van Eerdewijk and Danielsen 2015). Policy solutions can also help to safeguard against other avoidable negative effects of mechanization. For example, a sound legal framework can ensure that service providers stick to agreements and knowledge and skills development of tractors operators and technicians can reduce the risks related to tractor breakdowns and sensitize about the preservation of fragile soils (Daum and Birner 2017).

\subsubsection{Limitations of using participatory impact diagrams}

While the qualitative approach of this study has helped to unravel new perspectives on the effects of mechanization and, uniquely, to provide a better understanding of causal impact chains, the approach has limitations as well. For example, while it indicates how often certain impacts are mentioned, it provides no information on the magnitude of the impacts. Future studies may ask participants of FGDs to rank effects or to distribute, for example, checker pieces to create "magnitude towers" on the severity of effects. Moreover, while the approach helps to explore the perceived impacts of mechanization, thus giving respondents a voice, such an approach may underestimate aspects that are not felt by respondents. For example, while many women reported a decline in available firewood, men did not, potentially because they do not feel this effect due to a gender division of labor. Similarly, other aspects, which are not directly experienced, may be neglected. For example, while respondents highlighted the negative effects of deforestation, savannah conversion was not mentioned, although it can equally cause greenhouse gas emissions and threaten wildlife (Searchinger et al. 2015). Also, slowly shifting gender roles due to mechanization (as observed by Kansanga et al. 2019) may be neglected, and more abstract concepts such as rural development and land inequality, which are difficult to observe, may not be reported or attributed to mechanization.

While some aspects may have been neglected, others may have been exaggerated or attributed wrongly to mechanization. Some effects that respondents ascribed to mechanization may be caused by factors that unfold simultaneously alongside mechanization but are independent of it. For example, yield decline in the long term may, to some extent, also occur without mechanization in the absence of soil fertility management. Similarly, the narrative of mechanization leading to deforestation and, subsequently, more irregular rainfall may reflect participant's views on a phenomenon they are trying to make meaning of but may not be true - although deforestation can indeed change local climates (Searchinger et al. 2015). Also, the observation of the research participants that mechanization reduces crime and violence is likely to have many more contributing factors other than just mechanization. Thus, regarding some of the identified impacts, it remains a challenge to distinguish between experienced and "real" impacts of mechanization and respondent's views on mechanization and what perceived effects are due to mechanization, and what is due to other factors which unfold collinear to mechanization. Given these limitations as well as the heterogeneity of effects due to variations in local factors, we understand this paper as a first explorative study of potential effects, which can guide future research from different 
scientific disciplines concerned with agricultural, rural, and environmental development in Africa.

\section{Conclusion}

Despite having the potential to change the face of African farming and rural areas fundamentally, the effects of agricultural mechanization have not been studied comprehensively. Drawing on qualitative evidence from 129 focus group discussions in 87 villages in four African countries, this study is the first to take a holistic view of the effects of mechanization. The results suggest that mechanization has more far-reaching agronomic, environmental, and socioeconomic consequences than commonly assumed. The results suggest that many of the changes related to mechanization will be positive. However, some can be negative in the absence of complementary research efforts and policy measures. As highlighted by the FAO (2013), agricultural mechanization strategies are therefore needed for each African country that provides "a framework for making decisions on how to allocate resources, how to address current challenges, and how to take advantage of opportunities that arise" (p.xii). As noted by the FAO and emphasized by the findings from this study, such mechanization strategies have to consider all three pillars of sustainability. This will help to ensure that mechanization contributes to an African agricultural transformation that is sustainable from a social, economic, and environmental perspective.

Supplementary Information The online version contains supplementary material available at https://doi.org/10.1007/s13593-020-00651-2.

Acknowledgments We are grateful for the financial support from the "Program of Accompanying Research for Agricultural Innovation" (PARI), which is funded by the German Federal Ministry of Economic Cooperation and Development (BMZ). We are grateful for excellent feedback from Prof. Dr. Regina Birner as well as numerous Ph.D. students at the division "Social and Institutional Change in Agricultural Development" of the University of Hohenheim.

\section{Compliance with ethical standards}

Data availability All data generated or analyzed during this study are included in this published article.

Funding The study was funded by the "Program of Accompanying Research for Agricultural Innovation" (PARI), which is funded by the German Federal Ministry of Economic Cooperation and Development (BMZ) under grant number 2014.0690.9. Open Access funding enabled and organized by Projekt DEAL.

Conflict of interest The authors declare that they have no conflict of interest.
Authors' contribution Conceptualization: T.D., O.K., F.A.O.; methodology: T.D.; investigation: Y.P.A., G.F.C., P.H., R.C.Z., G.K., L.M, A.O.K., C.D., Y.N., A.A.W.; formal analysis: T.D., Y.P.A., G.F.C., P.H., R.C.Z., G.K., L.M, A.O.K., C.D., Y.N., A.A.W.; writingoriginal draft: T.D.; writing - review and editing: T.D., Y.P.A., G.F.C., P.H., R.C.Z., G.K., L.M, A.O.K., C.D., Y.N., A.A.W., O.K., F.A.O.; visualization: T.D.; funding acquisition: T.D., O.K., F.A.O.; supervision and project administration: T.D., F.A.O.

Research involving human participants The study was conducted according to the guidelines laid down in the 1964 Helsinki Declaration and its later amendments and the ethics committee of the University of Hohenheim.

Informed consent All study participants gave informed consent to participate in the study.

Consent for publication Individuals in the images shown (Fig. 1) gave their consent for publication.

Open Access This article is licensed under a Creative Commons Attribution 4.0 International License, which permits use, sharing, adaptation, distribution and reproduction in any medium or format, as long as you give appropriate credit to the original author(s) and the source, provide a link to the Creative Commons licence, and indicate if changes were made. The images or other third party material in this article are included in the article's Creative Commons licence, unless indicated otherwise in a credit line to the material. If material is not included in the article's Creative Commons licence and your intended use is not permitted by statutory regulation or exceeds the permitted use, you will need to obtain permission directly from the copyright holder. To view a copy of this licence, visit http://creativecommons.org/licenses/by/4.0/.

\section{References}

Adu-Baffour F, Daum T, Birner R (2019) Can small farms benefit from big companies' initiatives to promote mechanization in Africa? A case study from Zambia. Food Policy 84:133-145. https://doi.org/ 10.1016/j.foodpol.2019.03.007

Alves BJ, Madari BE, Boddey RM (2017) Integrated crop-livestockforestry systems: prospects for a sustainable agricultural intensification. Nutr Cycl Agroecosys 108(1):1-4. https://doi.org/10.1007/ s10705-017-9851-0

Baudron F, Sims B, Justice S, Kahan DG, Rose R, Mkomwa S, Kaumbutho P, Sariah J, Nazare R, Moges G, Gérard B (2015) Reexamining appropriate mechanization in Eastern and Southern Africa: two-wheel tractors, conservation agriculture, and private sector involvement. Food Secur 7(4):889-904. https://doi.org/10.1007/ s12571-015-0476-3

Baudron F, Misiko M, Getnet B, Nazare R, Sariah J, Kaumbutho P (2019) A farm-level assessment of labor and mechanization in Eastern and Southern Africa. Agron Sustain Dev 39(2):17. https://doi.org/10. 1007/s13593-019-0563-5

Baudron F, Nazare R, Matangi D (2019b) The role of mechanization in transformation of smallholder agriculture in Southern Africa: experience from Zimbabwe. In: Transforming Agriculture in Southern Africa. Routledge, London, pp 152-160

Benin S (2015) Impact of Ghana's agricultural mechanization services center program. Agric Econ 46(S1):103-117. https://doi.org/10. 1111/agec.12201

Berhane G, Dereje M, Minten B et al (2017) The rapid-but from a low base-uptake of agricultural mechanization in Ethiopia: patterns, 
implications and challenges. Ethiopia Strategy Support Program Working Paper 105. International Food Policy Research Institute, Washington

Biggs S, Justice S (2015) Rural and agricultural mechanization: a history of the spread of small engines in selected Asian countries. IFPRI Discussion Paper 1443. International Food Policy Research Institute, Washington

Binswanger HP (1986) Agricultural mechanization: a comparative historical perspective. World Bank Res Obser 1(1):27-56

Binswanger HP, Donovan G (1987) Agricultural mechanization: issues and options. World Bank, Washington

Bitsch V (2005) Qualitative research: a grounded theory example and evaluation criteria. J Agribusiness 23(1):75

Cossar F (2019) Impact of mechanization on smallholder agricultural production: evidence from Ghana. 3rd Annual Conference of the Agricultural Economics Society, 15-17 April, University of Warwick, England See: https://ageconsearch.umn.edu/record/ $289657 / ? \ln =$ en

Daum T, Birner R (2017) The neglected governance challenges of agricultural mechanisation in Africa-insights from Ghana. Food Secur 9(5):959-979. https://doi.org/10.1007/s12571017-0716-9

Daum T, Birner R (2020) Agricultural mechanization in Africa: myths, realities and an emerging research agenda. Global Food Security 26: 100393. https://doi.org/10.1016/j.gfs.2020.100393

Daum T, Capezzone F, Birner R (2020) Using smartphone app collected data to explore the link between mechanization and intra-household allocation of time in Zambia. Agr Hum Values. https://doi.org/10. 1007/s10460-020-10160-3

De Groote H, Marangu C, Gitonga Z (2018) Trends in agricultural mechanization in Kenya's maize production areas from 1992-2012. AmaAgr Mech Asia AF. 49(4):20-32

Diao X, Cossar F, Houssou N, Kolavalli S (2014) Mechanization in Ghana: emerging demand, and the search for alternative supply models. Food Policy 48:168-181. https://doi.org/10.1016/j. foodpol.2014.05.013

Dixon JA, Gibbon DP, Gulliver A (2001) Farming systems and poverty: improving farmers' livelihoods in a changing world. Food \& Agriculture Organization, Rome

Douthwaite B, Schulz S, Olanrewaju A et al (2007) Impact pathway evaluation of an integrated Striga hermonthicacontrol project in northern Nigeria. Agr Sys 92:201-222. https://doi.org/10.1016/j. agsy.2006.03.007

FAO (2013) Agricultural mechanization in sub Saharan Africa: guidelines for preparing a strategy. Integrated Crop Management 22. Food and Agriculture Organization, Rome.

Fischer G, Wittich S, Malima G, Sikumba G, Lukuyu B, Ngunga D, Rugalabam J (2018) Gender and mechanization: exploring the sustainability of mechanized forage chopping in Tanzania. J Rural Stud 64:112-122. https://doi.org/10.1016/j.jrurstud.2018.09.012

Garbarino S, Holland J (2009) Quantitative and qualitative methods in impact evaluation and measuring results. GSDRC, University of Birmingham, Birmingham

Hazell P, Poulton C, Wiggins S, Dorward A (2010) The future of small farms: trajectories and policy priorities. World Dev 38(10):13491361. https://doi.org/10.1016/j.worlddev.2009.06.012

Houssou N, Chapoto A (2015) Adoption of farm mechanization, cropland expansion, and intensification in Ghana. Agriculture in an Interconnected World. Conference of the International Association of Agricultural Economists, August 9-14, Milan, Italy. See here: https://ageconsearch.umn.edu/record/211744

Jaleta M, Baudron F, Krivokapic-Skoko B, Erenstein O (2019) Agricultural mechanization and reduced tillage: antagonism or synergy? Int J Agr Sustain 17(3):219-230. https://doi.org/10.1080/ 14735903.2019.1613742
Jansen AJ (1969) Social implications of farm mechanization: final report on a cross-national research. Sociol Ruralis 9(4):340-407

Kansanga M, Andersen P, Kpienbaareh D, Mason-Renton S, Atuoye K, Sano Y, Antabe R, Luginaah I (2018) Traditional agriculture in transition: examining the impacts of agricultural modernization on smallholder farming in Ghana under the new Green Revolution. Int J Sustain Dev World Ecol 26(1):11-24. https://doi.org/10.1080/ 13504509.2018.1491429

Kansanga M, Andersen P, Atuoye K, Mason-Renton S (2018b) Contested commons: agricultural modernization, tenure ambiguities and intra-familial land grabbing in Ghana. Land Use Policy 75:215224. https://doi.org/10.1016/j.landusepol.2018.03.047

Kansanga MM, Mkandawire P, Kuuire V, Luginaah I (2019) Agricultural mechanization, environmental degradation and gendered livelihood implications in northern Ghana. Land Degrad Dev 31(11):14221440. https://doi.org/10.1002/ldr.3490

Kariuki J, Njuki J (2013) Using participatory impact diagrams to evaluate a community development project in Kenya. Dev Pract 23(1):90 106. https://doi.org/10.1080/09614524.2013.753031

Kate S (2009) Agro-ecological zones of Africa. Harvard Dataverse V2. https://doi.org/10.7910/DVN/HJYYTI

Kergna A, Nientao A, Ongoiba B (2020) Mechanization and skills development for productivity growth, employment and value addition: insights from Mali. FARA research reports 5(19). Forum for Agricultural Research in Africa (FARA), Accra

Kirui O (2019) The agricultural mechanization in Africa: micro-level analysis of state drivers and effects. ZEF-Discussion Papers on Development Policy 272. Center for Development Research, Bonn

Lado C (1992) Female labour participation in agricultural production and the implications for nutrition and health in rural Africa. Soc Sci Med 34(7):789-807. https://doi.org/10.1016/0277-9536(92)90366-X

Malabo Montpellier Panel (2018) Mechanized: transforming Africa's agriculture value chains. International Food Policy Research Institute (IFPRI) and Malabo Montpellier Panel, Dakar, Senegal

Mano Y, Takahashi K, \& Otsuka K (2020) Mechanization in land preparation and agricultural intensification: The case of rice farming in the Cote d'Ivoire. Agric Econ 51(6):899-908

PPMA (2015) Evaluation de la production vivrière 2015 et des perspectives alimentaire pour 2016 au Bénin. Rapport Général 1. Programme de promotion de la mécanisation agricole, Cotonou

Searchinger TD, Estes L, Thornton PK, Beringer T, Notenbaert A, Rubenstein D, Heimlich R, Licker R, Herrero M (2015) High carbon and biodiversity costs from converting Africa's wet savannahs to cropland. Nat Clim Chang 5(5):481-486. https://doi.org/10.1038/ nclimate 2584

Sibhatu KT, Qaim M (2018) Meta-analysis of the association between production diversity, diets, and nutrition in smallholder farm households. Food Policy 77:1-18. https://doi.org/10.1016/j.foodpol.2018.04.013

Silva JV, Baudron F, Reidsma P, Giller KE (2019) Is labour a major determinant of yield gaps in sub-Saharan Africa? A study of cereal-based production systems in Southern Ethiopia. Agr Sys 174:39-51. https://doi.org/10.1016/j.agsy.2019.04.009

Sims B, Kienzle J (2016) Making mechanization accessible to smallholder farmers in sub-Saharan Africa. Environments 3(2):11. https://doi. org/10.3390/environments3020011

Sims B, Kienzle J (2017) Sustainable agricultural mechanization for smallholders: what is it and how can we implement it? Agriculture 7(6):50. https://doi.org/10.3390/agriculture7060050

Sims B, Hilmi M, Kienzle J (2016) Agricultural mechanization: a key input for sub-Saharan Africa smallholders. Integrated crop management 23. FAO, Rome

Sulieman HM (2015) Grabbing of communal rangelands in Sudan: the case of large-scale mechanized rain-fed agriculture. Land Use Policy 47:439-447. https://doi.org/10.1016/j.landusepol.2015.04.026 
Takeshima H, Edeh HO, Lawal AO, Isiaka MA (2015) Characteristics of private-sector tractor service provisions: insights from Nigeria. Dev Econ 53(3):188-217. https://doi.org/10.1111/deve.12077

Takeshima H, Lawal A (2018) Overview of the evolution of agricultural mechanization in Nigeria (Vol. 1750). Intl Food Policy Res Inst, Washington

Takeshima H, Nin-Pratt A, Diao X (2013) Mechanization and agricultural technology evolution, agricultural intensification in subSaharan Africa: Typology of agricultural mechanization in Nigeria. Am J Agric Econ 95(5):1230-1236

Van Eerdewijk A, Danielsen K (2015) Gender matters in farm power. KIT, Amsterdam
Wang X, Yamauchi F, Huang J (2016) Rising wages, mechanization, and the substitution between capital and labor: evidence from small scale farm system in China. Agric Econ 47(3):309-317. https://doi.org/ 10.1111/agec. 12231

World Bank (2017) World Bank Indicators from https://data.worldbank. org/indicator/AG.YLD.CREL.KG. Accessed 10 Aug 2020

Publisher's note Springer Nature remains neutral with regard to jurisdictional claims in published maps and institutional affiliations. 